\title{
Difficulties and Solutions to the Installation of Elevators in Existing Houses
}

\author{
Mengya Li \\ China Jiliang University \\ Zhejiang, Hangzhou \\ 843708969@qq.com
}

\begin{abstract}
The installation of elevators in existing houses is not only based on public policy considerations, but also to compensate for the negative consequences of strict control in the past. Based on the present situation and rationality analysis of adding elevator, this paper starts from the problems such as the difficulty of coordination of users' interests, the complexity of examination and approval procedure, the balance between private right and public interest. Through empirical analysis, gradient design to resolve interest disputes and change the role of government. Introduce market competition mechanism and seek feasible solutions to installing elevators.
\end{abstract}

Keywords_Existing residence; Installing elevators; An aging society; Public interest

\section{INTRODUCTION}

The report of the 19th National Congress of the Communist Party of China pointed out that the basic contradiction in China at this stage is the incompatibility between the growing material and cultural needs of the people and the backward productivity. Most of the existing houses were built in the 1950s and 1980s. At that time, lift installation was prohibited from multi-story buildings due to policy restrictions. As China's aging problem gradually became prominent, non-lift became an important obstacle for the elderly to travel. The 2018 government works to report put forward: "orderly promotion of 'urban villages', renovation of old residential areas, improvement of supporting measures, and encouragement of conditional addition of elevators. The safety management measures for elevators in Hangzhou explicitly encourage the installation of elevators. With the advance of China's "9073" pension goal, the installation of elevators for existing residential buildings is not only based on the consideration of public policies, but also makes up for the original strict control policies, which is of the great significance of the protection for family pension.

\section{THE RATIONALITY ANALYSIS OF EXISTING BUILDINGS WITH ELEVATORS}

\section{A. The aging problem is serious}

According to the statistical results of the population data onto the national bureau of statistics in 2018, the current population of China are 240.9 million people aged 60 and above, accounting for $17.3 \%$ of the total population, among which 158.31 million people aged 65 and above, accounting for $11.4 \%$ of the total population,[1] has exceeded the international aging standard. When China association with old science and technology was investigating and visiting places such as Beijing, Shanghai, Nanjing , and Harbin, it was found that the design of old buildings had become the main obstacle for the elderly to travel and had become a common social problem. It is an important measure to solve the problem of aging people's livelihood to let the elderly out of the house, improve living conditions and improve the practical functions of existing houses.

\section{B. Solving overcapacity}

China's economy has turned from a stage of rapid growth of a stage of high-quality development. The report on the 19th national congress of the communist party of China (CPC) proposed that China should continue to deepen the reform of supply-side structure in the future development, adhere to the principle of eliminating production capacity, inventory and leverage, and achieve the dynamic balance between supply and demand. In 2018, China's crude steel output still ranks first in the world. The excess steel industry not only aggravates China's environmental burden, but also easily forms vicious market competition and a triggers price war. The ministry of industry and information technology has proposed that in 2018, the steel industry should unswervingly reduce overcapacity, and the addition of elevators to existing buildings has become an important export to address excess capacity. According to the statistics of the relevant departments of the state, there are about 8 billion square meters of old residential buildings built from 1980 to 2000, and more than $70 \%$ of old elevators in cities and towns where the elderly live have no elevators. According to the preliminary budget, the gap of the national elevator market is nearly 40 million [2]. The huge elevator market consumes a lot of steel, and at the same time, it will drive the development of related industries.

\section{Improving the living environment}

In recent years, China advocates the development of a green economy and combines economic development with environmental protection to achieve sustainable development. With the acceleration of urbanization, a large number of old residential areas are vacant or used for other purposes due to low commercial value, resulting in a waste of resources. Especially in the old city, the development of early, complete supporting facilities, life, services, education and so on 
compared to the new city is more perfect, old buildings with elevators convenient living conditions will make the purchase of heat to ease a little, at the same time to the second-hand housing market has a role in promoting.

\section{DIFFICULTIES IN INSTALLING ELEVATORS IN EXISTING BUILDINGS}

The installation of elevators in existing buildings has become a hot spot, which is supported by the general public, especially the elderly in the old residential areas. Guangzhou, Shanghai, Hangzhou, Xiamen, Nanjing and other places have issued relevant policies and provided financial subsidies to encourage and guide units or owners to apply for it. Taking Hangzhou as an example, the implementation opinions of the general office of Hangzhou municipal people's government on the installation of elevators for existing residential buildings in Hangzhou urban area proposed that "the government will give 200,000 yuan/sets of subsidies for the installation of elevators for existing residential buildings with no single property right over four floors within the urban area", and provide pipeline subsidies for those meetings the policy conditions. However, in practice, there are many difficulties in installing elevators in existing residential buildings. From the perspective of the development status of installing elevators, common problems are:

\section{A. Household opinions and interests are difficult to coordinate}

The installation of elevators in existing houses is not only a technical issue, but also involves the balance of interests between high-rise residents and low-rise households. The demand for installing elevators is mainly concentrated on the elderly group. The higher the number of floors, the higher the cost, plus the elevator shaft and the maintenance cost in the later period, even if there is government subsidy, it will be a lot of money cost. In order to control and reduce contradictions from the source, the government set an "one-vote veto" to some extent to prevent the promotion of the installation of elevators. During the announcement period, once the industry presided over the opposition, the installation of elevators would become a bubble. The rule of law achieves a balance between the minority and the majority by establishing voting rules and guaranteeing the implementation of these rules of state coercive power. If any member's unanimous consent is premise, the society will be stagnant because it cannot form any decision. [3]

\section{B. The approval procedures are complicated}

In practice, the installation of elevators takes a long time and involves many problems. The residents discuss and communicate with relevant government departments, and issue to design plans and supervise management. Due to the asymmetry of information, residents do not understand the government's operating system. For some pilot cities, there is no detailed guidance on the procedures for installing elevators. In the approval process, it involves departments such as housing construction, fire protection, quality supervision, planning, development and reform. The complicated procedures and numerous links will greatly increase the workload of the implementation subject, and it also means the uncertainty of the review process, thus hindering the effective implementation of the installation process. [4]There are as many as 40 seals within 22 months from the application of the approval. For the elderly, long-term running is a burden of itself., reduced the willingness of the owner to install the elevator.

\section{The "Double Two-thirds principle" applies to the disputes}

Some scholars believe, the establishment of existing residential elevators is a civil act, rather than Non-government behavior, but also non-social public welfare behavior, it's a private matter between owners. The "principle of the double majority" is not only a serious misunderstanding of the property law, but also causes the Relevl Ant policies To is contrary to the relevant legal provisions in the general provisions of civil law, resulting in the Noification of contradictions. [5] some scholars who believe existing residential installation elevator is the cause of people's livelihood, belongs to the category of public governance, should be based on the wishes of the majority, and the "Property law" on the establishment of voting rights, should not be a simple conflation with the policy of the relevant administrative law. [6]

However, the practice of the local preference for the "double two-thirds principle", although the path taken is different, in fact: Hangzhou, Shenzhen will be equipped with elevators as part of the building accessories, and Changzhou, Harbin, the installation of elevators attributed to special equipment, by the special Equipment testing and research institute to supervise and manage, The reason why the Government has not attributed it to the building appendages is mainly based on public policy considerations, and the existing residential additional elevators have gone beyond private rights and do not fall within the scope of the adjustment of the property law. However, "Changzhou existing residential installation elevator implementation measures (trial)" (draft for comments sixth), but also stipulated that "The addition of elevators to existing residential buildings shall be subject to the consent of the owners whose exclusive parts of this building or this unit account for more than two-thirds of the total building area and more than two-thirds of the total number of persons...."

\section{SOLUTIONS TO THE PROBLEM OF ADDING ELEVATORS TO EXISTING BUILDINGS}

\section{A. Gradient design to address cost-sharing}

The most important thing about adding elevators to households is the balance of interests, the degree of benefit of high-rise households and lower-level households is different, the proportion of funds assessed will vary, and the gradient design is more reasonable. High-rise households because of the addition of elevators to profit more, in addition to life more convenient, add elevators will also cause real estate value added, so the burden of capital is higher than other owners, the lower the floor, the lower the proportion of fees paid for the 
installation of elevators. One floor, two floors of households do not have to pay the cost of additional elevators, and because of the addition of elevators caused by the devaluation of the property or affect the lighting, resulting in noise, and so on, high-rise tenants can give reasonable compensation. In order to improve the satisfaction and participation of a layer of households, owners can negotiate the top-level space with a layer of households as compensation.

The maintenance and maintenance costs of the additional elevators can be prorated through the signing of agreements. In order to avoid the act of "hitchhiking", a "one family, one card" system can be adopted. Can also learn from the Beijing "bus" elevator operation mode, that is, the government free installation, residents do not have to pay elevator construction and maintenance costs, take the elevator down the stairs to pay a fee by credit card. In addition, the introduction of the "Surrogate rental" model, the enterprise is responsible for the purchase and installation, the owner only pays rent and maintenance costs. Households can also be rented, by the way, to collect rent, for the late maintenance of elevators and other subsequent operation.

\section{B. Streamlining the approval process and providing a "one-stop" service}

In view of the complex issue of approval, to simplify and convenience as the principle, for the eligible old residential installation elevator applicants to provide a ' one-stop ' service; "The executive opinion of the Office of the Hangzhou Municipal People's government on carrying out the work of Hangzhou city existing residential loading elevator" puts forward that the relevant departments may conduct joint examination and issue joint examination opinions, For those involved in the transformation of related pipelines, the relevant units to open green channels, according to the joint review opinion, priority processing. "Harbin City existing residential installation elevator work Implementation Plan" proposed in the existing residential installation elevator does not set up administrative license and approval procedures. Shanghai Multi-Department jointly issued document No. 833, the old community to add elevators approval link from 46 to 15, the relevant departments also reduced to 4.[7]

In addition, the government should change the concept from a manager to a supervisor, and strengthen the supervision of the installation of elevators in and after the event. The so-called in-process supervision, that is, the relevant departments to the elevator construction process involving safety issues in strict accordance with the construction process and design supervision; Post-supervision is to carry out effective supervision on the big data platform through the repair, maintenance, inspection and other work of the installed elevator.

\section{Top-level design to clarify the application of the law}

Due to the dispute of "double majority principle", the essence of the dispute is the difference in the cognition of elevator attributes, and the lack of the rules of superior law. Japan in the act of building distinguish all specified by building structure for distinguish all members share building part (corridor, stair room, elevator room, etc.), due to the underlying ownership of shall not be used as independent, so in principle as the common parts of all the proprietary parts for all the distinction between all people share. [8]Although there is no specific elevator law in Japan, the building standards law and the labor safety law contain elevator management regulations, and the implementation order of the building standards law also makes detailed provisions on elevator construction application procedures, well setting and structure in buildings. [9]

However, in China, without an accurate understanding of the exclusive parts, it is very difficult to explain the common parts, and the judicial interpretation does not clarify the scope of the common parts. According to our country "property law" the 70th regulation, the owners have the right to the exclusive right of exclusive parts in addition to the building, for the common parts shall enjoy the right of common and common management. Whether to add elevator to belong to building appurtenant part, law does not make clear provision, still need to make clear. If the elevator is an inseparable part of the external space of the residence, the owner has a joint right to the elevator, and it is more justifiable to apply article 76 of the property law.

In addition, based on the support and support of the installation of elevators, various regions in accordance with local conditions to launch the installation of elevator guidance and local legislation, but because in the application of the law, there is no uniform standard, so it is proposed to formulate relevant laws from the national level, so that existing residential installation of elevators in the specific practice has laws to follow, to resolve conflicts and disputes. It is suggested that the application space of this kind of situation can be reserved in the sub-provisions of the civil code, that is, "if other laws provide otherwise, the law shall apply".

\section{Introduction of market competition mechanisms}

Relying solely on owners to complete from the application to the installation of supervision work, time-consuming, low efficiency, and the most prominent feature of marketization is the cost advantage brought about by economies of scale. According to statistics, at present, China has about 600 elevator ladder manufacturers, about 11,000 provide elevator installation and maintenance enterprises; can be combed to these enterprises, to create a professional team. Owners can entrust a professional team, on the one hand responsible for exchanges with government agencies, submit a variety of approval documents, on the other hand, coordinate the installation of elevators involved in the pipeline, lines, such as alterations and installations, and responsible for the supervision of additional elevator work. Although the owner has to pay the funds entrusted by the professional team, the cost of the balance and the benefits of competition between the professional teams are sufficient to cover the funds paid by the owners, compared to the time consuming and labor of the owners alone.

\section{SUMMARY}

Existing residential installation elevator has been the general trend, the Government attaches great importance to the existing residential installation the elevator work, more out of 
public policy considerations, rather than based on meaning autonomy, but also to make up for the adverse consequences of compulsory control, to achieve the correction of rigid control. At this stage, all over the introduction of relevant guidance, simplify the installation of elevator approval process, through high-level work to obtain more voice, promote the implementation of existing residential plus elevators, and strive to create a liveable environment for the elderly, in order to enhance people's life happiness index.

\section{REFERENCES}

[1] http://www.360doc.com/content/18/0329/07/20898461_741155006.sht m China population data (2018).

[2] https://house.focus.cn/zixun/ae3854d47e4fbeba.html. Existing residential add elevator demand, the future market size can exceed trillion!

[3] Hu Jianmiao, "the balance between the minority and the majority under the rule of law--starting from installing elevators in old buildings", people's rule of law, vol.pp.71, September, 2018
[4] Hu Weiqiang, how the government ACTS in an aging society -- a case study of the dilemma of installing elevators in old residential buildings, China law reviews, vol.pp.190-200, January, 2018.

[5] Chen Shaofang, analysis on the applicable legal issues of adding elevators to existing residential buildings, property management, vol.pp.60--67 ,May, 2017.

[6] Yang Tuo, reflections on the dilemma of adding elevators to existing residential buildings under the phenomenon of "one vote no" -- centered on article 78 of property law $>$, science and technology association BBS, vol.pp54-56, November, 2017.

[7] "Difficult! Why is it difficult to install an elevator at the beginning, then the process, and finally the result?" "elevator industry information," August 6, 2018.

[8] [Japan] Wo Qirong , [Japan] Youquan Hengbuding, Luo Li translation, new property law, China legal publishing house, 2008 edition, vol.pp. 540-541 .

[9] Zhang huan, Tang baosheng. introduction to Japanese elevator management regulation", proceedings of academic exchange meeting on building technology and management in November 2015, November 2015. 